\title{
Estimating of Streamflow Using Multispectral Satellite Imagery
}

\author{
Jin-Gyeom Kim and Boosik Kang* \\ Dankook University, \#152 Jukjeon-ro, Suji-gu, Yongin-si, Gyeonggi-do, Republic of Korea \\ ${ }^{*}$ Corresponding author
}

\begin{abstract}
In this study streamflow along the river course was reconstructed using Sentinel Satellite imagery. The Sentinel satellite is being operated by ESA(European Space Agency) and provide the imagery with 18 multispectral bands. The near infrared imagery with $10 \mathrm{~m}$ resolution captured on Feb. 8, 2016 which can identify water body from ground surface was utilized for this study. The experiments were implemented at the $26.7 \mathrm{~km}$ section from Yangpyeong Bridge to Yeoju Bridge along the South Han River. The streamflows at the reference surveying points with river cross sections ready were estimated using the river width observed from satellite imagery, the pre-calibrated relationships of the stage vs width and stage vs cross-section and the water surface slopes replaced for the energy slopes.
\end{abstract}

Keywords-satellite; remite sensing; streamflow; sentinel

\section{INTRODUCTION}

The use of satellite remote sensing information is becoming more critical for acquiring hydrological information in ungauged area, complementing missing values, and for measuring synchronized hydrological components in largescale area. The reconstruction of hydraulic measurement using satellite remote sensing have recently received much attention especially for the purpose of identifying spatial and temporal hydrologic connectivity. Despite the relatively low accuracy at the individual measuring point, the satellite imagery covers large area simultaneously which offsets the disadvantages compared to ground measurements.

\section{STUDY AREA AND DATA}

\section{A. Study Area}

Study area is the $26.7 \mathrm{~km}$ section from Yangpyeong Bridge to Yeoju Bridge along the South Han River. This section has 3 river bridges with ground gauge and 2 large weirs.

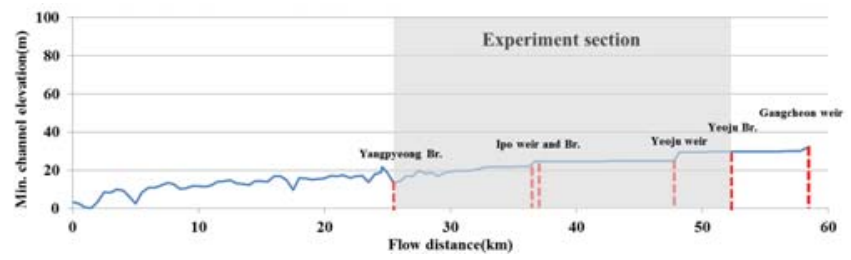

FIGURE I. EXPERIMENT SECTION CHARACTERISTICS

\section{B. Remote Sensing and in Situ Data Sources}

The Sentinel-2A satellite is being operated by ESA(European Space Agency) and provide the imagery with 18 multispectral bands. The near infrared and short wave infrared imagery with 10m resolution captured on Feb. 8, 2016 which can identify water body from ground surface was utilized for this study.

Hydraulic radius and cross sectional area of flow were estimated using bathymetric cross sectional measurements from the HEC-RAS model database. It has bathymetry for the rivers every $500 \mathrm{~m}$ in the experiment section.

Ground gauge data collected from Yangpyeong, Ipo and Yeoju Bridges. These gauges provide water elevation and discharge measurements. Additional data collected at the out of the experiment section for the measuring water surface slope

\section{METHODOLOGY}

\section{A. Flow Hydraulics}

Manning's Equation yields flow velocity as the product of water surface slope, hydraulic radius and the roughness coefficient. It is an empirical equation, but well used in the hydrological sciences and in remote sensing estimates of discharge as in [1], [2], [3]. Multiplying flow velocity by channel cross sectional area drive discharge from following equation (1)

$$
\mathrm{Q}=\mathrm{A} \frac{1}{n} R^{2 / 3}\left(\frac{\partial h}{\partial x}\right)^{1 / 2}
$$

Values of roughness coefficient for such geomorphologies are estimated to range from 0.018 to 0.035 [4], [5]. We selected a value of $n$ equal to 0.03 for natural streams in fair condition.

\section{B. Normalized Difference Water Index}

Normalized difference water index (NDWI) may refer to one of at least two remote sensing derived indexes related to liquid water. [6] proposed NDWI using near infrared(NIR) and short wave infrared(SWIR) wavelengths. NDWI can be useful for remote sensing water body detection from space.

$$
\mathrm{NDWI}=\frac{N I R-S W I R}{N I R+S W I R}
$$

NDWI represent bright surface with no vegetation or water content from -1 to 0 , water content from 0 to 1 


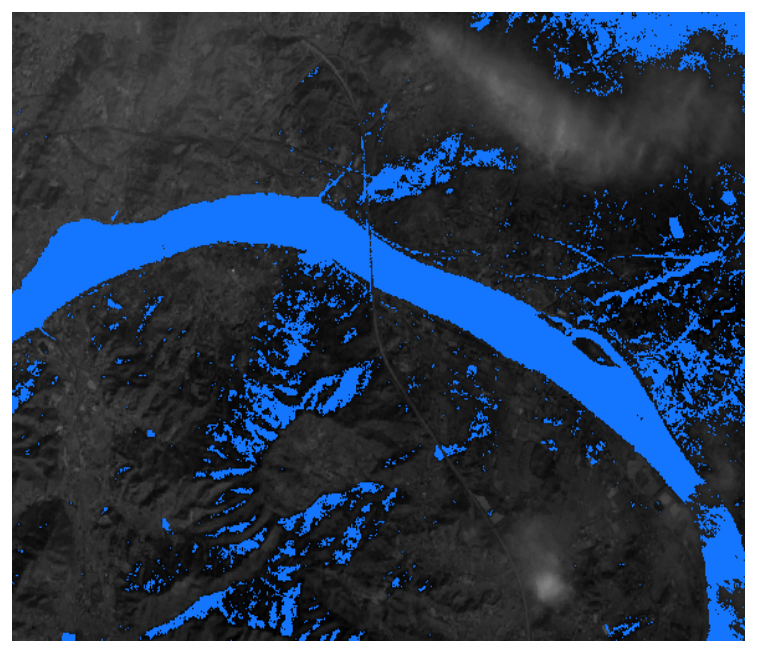

\section{RESULT}

The streamflow at the reference surveying points with river cross sections ready were estimated using the river width observed from satellite imagery, the pre-calibrated relationships of the stage vs width and stage vs cross-section and the water surface slopes replaced for the energy slopes. For minimizing uncertainties caused from the energy slope, the water surface slopes were measured from the water elevation gauged from the ground at 3 river bridges located in the middle of the experiment section (Figure III). Cross section selected common point without junctions of stream, separated sections by island in river, cloudy sections.

The discharge coefficient was calibrated and validated at the downstream and upstream section of the Ipo Bridge in the center. The relative error of the estimated streamflow at the validation section was $0.5 \%$ ( Table I).

FIGURE II. NDWI( $>0)$ AND NEAR INFRARED BASE MAP OF SENTINEL-2A IN PART OF EXPERIMENT SECTION

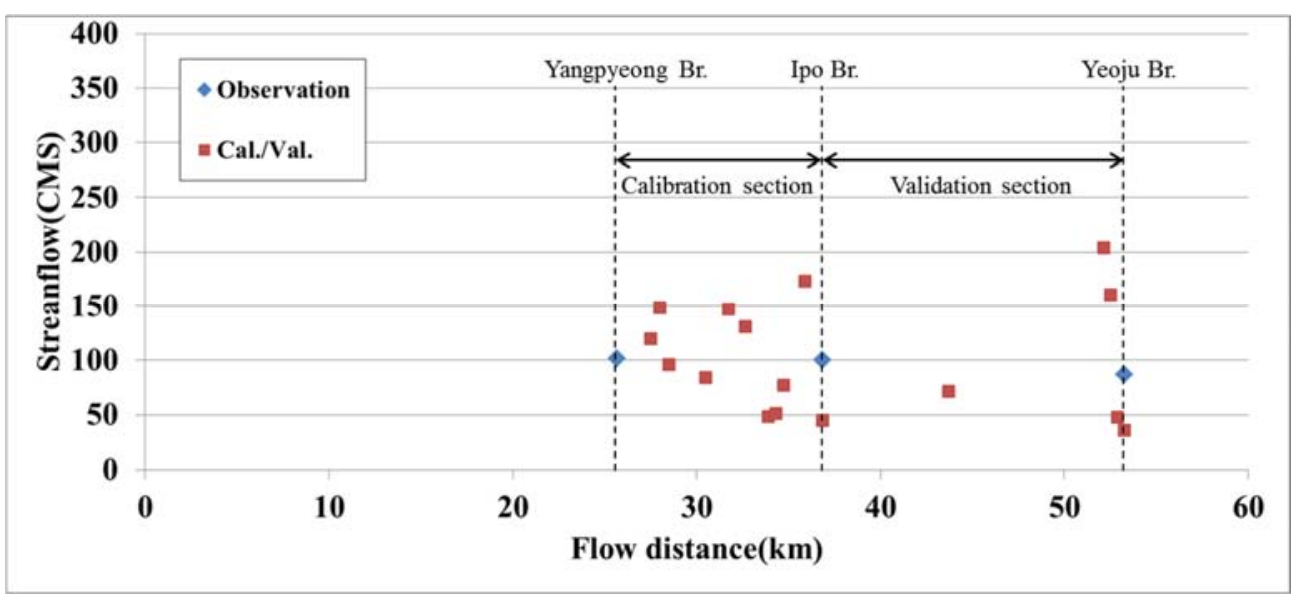

FIGURE III. DISCHARGE ESTIMATION WITH CALIBRATION AND VALIDATION AT EACH RIVER CROSS SECTION(SQUARES). OBSERVED DISCHARGE (DIAMONDS)

FIGURE IV. CALIBRATION AND VALIDATION RESULTS

\begin{tabular}{|c|c|c|c|c|c|}
\hline Section & $\begin{array}{c}\text { observed } \\
\text { discharge } \\
\left(\mathrm{m}^{3} / \mathrm{s}\right)\end{array}$ & $\begin{array}{c}\text { Estimated } \\
\text { discharge } \\
\left(\mathrm{m}^{3} / \mathrm{s}\right)\end{array}$ & Discharge coefficient & $\begin{array}{c}\text { Revised } \\
\text { discharge } \\
\left(\mathrm{m}^{3} / \mathrm{s}\right)\end{array}$ & $\begin{array}{c}\text { Relative error } \\
\text { (\%) }\end{array}$ \\
\hline Calibration & 100.9 & 147.0 & \multirow{2}{*}{0.693} & 101.9 & 1.0 \\
\hline Validation & 93.7 & 135.8 & & 94.1 & 0.5 \\
\hline
\end{tabular}

a. Discharges are sectional averaged values

\section{CONCLUSION}

Streamflow along the river course was derived using Sentinel-2A satellite imagery. NDWI used for water body detection and determined river width with cross sectional areas. The streamflows were estimated using the river width with the pre-calibrated relationships of cross sectional bathymetries. The discharge coefficient was calibrated and validated at the downstream and upstream sections. The relative error of the estimated streamflow at the validation section was $0.5 \%$. These results represent that possibility of streamflow measurement using multispectral satellite imagery. The additional experiment under the various flow regimes and with different band will supplement the practicality of the methodology.

\section{ACKNOWLEDGMENT}

This research was supported by a grant (15AWMPB079625-02) from Water Management Research Program funded by Ministry of Land, Infrastructure and Transport of Korean government. 


\section{REFERENCES}

[1] D. M. Bjerklie, D. Moller, L. C. Smith, S. L. Dingman, "Estimating discharge in rivers using remotely sensed hydraulic information," Journal of Hydrology, vol. 309, pp. 191-209, July 2005.

[2] G. LeFavour, D. E. Alsdorf, "Water slope and discharge in the Amazon River estimated using the shuttle radar topography mission digital elevation model," Geophysical Research Letters,vol. 32 , no. 17, September 2005.

[3] H. C. Jung et al., "Characterization of complex fluvial systems using remote sensing of spatial and temporal water level variations in the Amazon, Congo, and Brahmaputra rivers,” Earth surface process and landforms, vol 35, no. 3, pp. 294-304, Febrary 2010

[4] P. J. Ashworth et al., "Morphological evolution and dynamics of a large, sand braid-bar, Jamuna river, Bangladesh,” Sedimentology, vol. 47, pp. 533-555, june 2000

[5] M. L. Albertson, B. B. Simons, Section 7: Fluid mechanics, In Handbook of Applied Hydrology: A Compendium of Water-Resources Technology, Chow VT (ed). McGraw-Hill: New York, 1964

[6] B. C. Gao, "NDWI-A normalized difference water index for remote sensing of vegetation liquid water from space," Remote sensing of environment, vol. 58, no. 3, pp. 257-266, December 1996 